REPORT No. 66

\title{
GLUES USED IN AIRPLANE PARTS
}

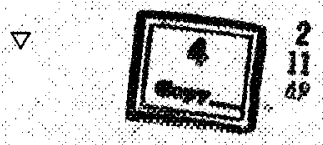

\section{NATIONAL ADVISORY COMMHTEE FOR AERONAUTICS}
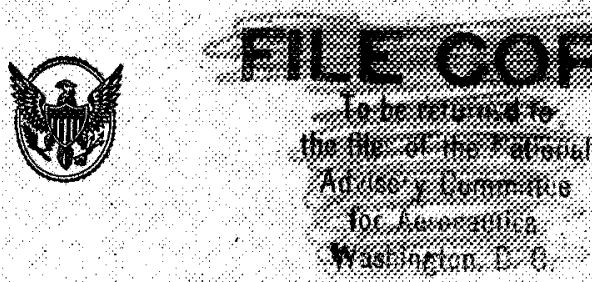

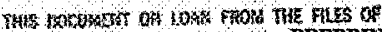

PREPRINT FROM FITH ANNUAL RBPORT

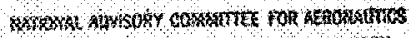

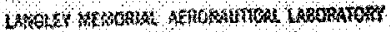

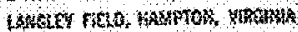

(

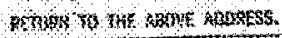

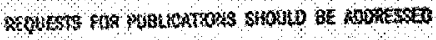

An $015 \%$ s.

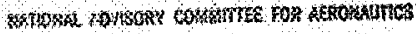

mostactsis Wsmonk 2,20 


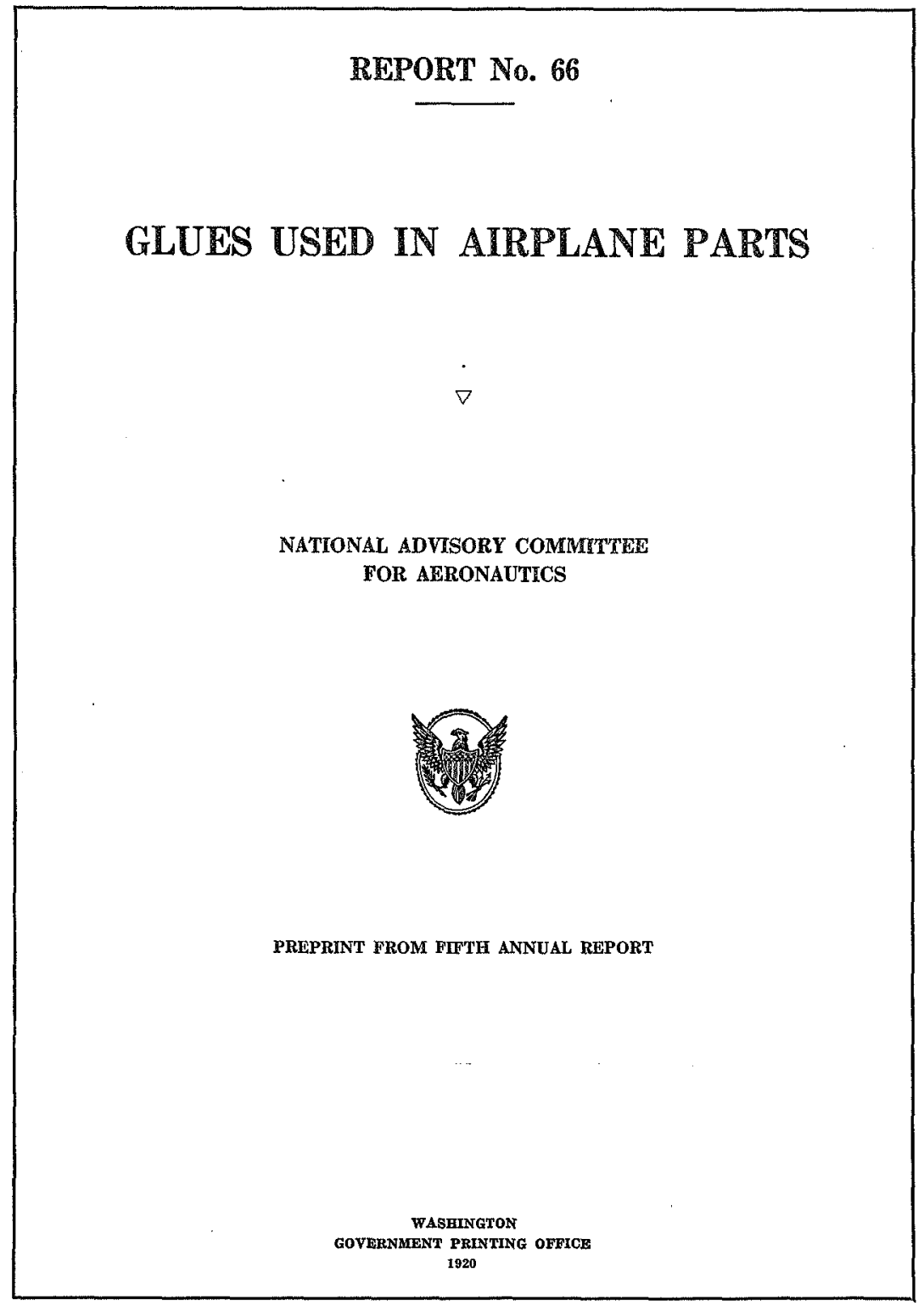




\title{
REPORT No. 66
}

\section{GLUES USED IN AIRPLANE PARTS}

\author{
COMPHED BY
}

S. W. ALLEN, Industrial Examiner in Forest Products and T. R. TRUAX, Wood Technologist

FOREST PRODUCTS LABORATORY

FOREST SERVICE

UNITED STATES DEPARTMENT OF AGRICULTURE

(In Cooperation with the University of Wisconsin) 


\section{CONTENTS.}

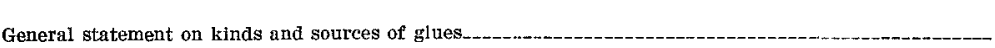

Animal glueswheir manufacture, preparation, and application

Manufacture of animal gltie

Mixing and application of animal glue._-

Strenglh of animal glue_-_-_-_-

List of references.

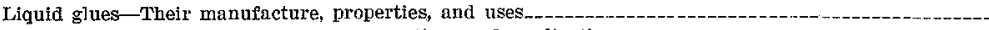

Casein glues-Their manufacture, preparation, and application

Types of casein glue..._.

Manufacture of casein

Mauufacture of glie..._-

Formula 4-A (Forest Froducts Laboratory) -

Method of Mixing

Description of materials

Prepared casein glues_..._-

Typé of mixer.

Applifeation of glue._...- 14

Pressure -

Storage of casein glues._..........

Strength and water-resistance._...-_._. 14

References on casein and casein glue_-_-_-

Blood albumin glues-meir manufacture, preparatior, and application

Wet glue process_-___. 16

Preparation of glue....

Application of glue._.

Pressing -

Precautions in the use of blood albumin glue

Dry glue process for thin veneer.

Preparation of glue layer.

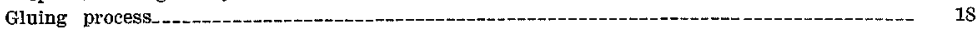

Advantages of this process.

Vegetable glue-Manufacture and use

Comparison of various types of glue

Testing glues.._-

Strength _-

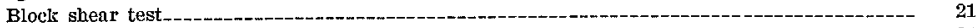

Plywood shear test__._.

Water resistance

Viscosity _.

Jelly strength______-

Odov'-

Keeping quality

Grease__.

Folm

Reaction to litmus...

Comparison with standard sample 


\section{REPORT No. 66.}

\section{GLUES USED IN AIRPLANE PARTS.}

By S. W. Attign and T. R. Truax.

This report was prepared for the National Advisory Committee for Aeronautics and presents the results of investigations conducted by the Forest Products Laboratory of the United States Forest Service, at the request of and with funds provided by the Bureau of Construction and Repair and the Bureau of Steam Engineering of the Navy Department, and the Bureau of Aircraft Production of the War Department. Some of the general statements are taken from the literature on glues existing previous to the time that the laboratory undertook this line of investigation.

\section{GENERAL STATEMENT ON KINDS AND SOURCES OF GLUE.}

There are many kinds of glue, sorne of which have been known for a long time. The kind to be used in any particular case depends upon the character of the material to be held together and upon the use to which the finished article is to be put. Strength, for instance, is usually the important requirement for glue to be used for joint work; cheapness may be more important than strength in the manufacture of low-grade plywood and other inexpensive artieles; and water-resistance is demanded of the glues to be used in airplanes, certain kinds of sporting goods, and other glued work which is to be exposed to the weather or to high hnmidity.

For the purpose of this discussion, glues will be divided into five types, which will be designated as follows:

1. Animal glues, which are made from the hides, hoofs, horns, bones, and fleshings of animals, principally cattle. These glues must be mixed with water and melted.

2. Liquid glues, which are commonly made from the heads, skins, bones, and swimming bladders of fish. Some liquid glues, however, are made from animal glne and from other materials. They come in prepared form ready for immediate use.

3. Vegetable glues, which are made from starch, usually cassava starch, and sold in powdered form. Ordinarily they require heating with water and alkali for preparation.

4. Casein glues, which are made from casein, lime, and certain other chemical ingredients. They are commonly sold in powdered form, requiring only the addition of water.

5. Blood albumin glues, which are made from black soluble blood albumin, a product recovered trom the blood of animals. These glues must be mixed just before use, since they deteriorate rapidly in standing.

\section{ANIMAL GLUES-THEIR MANUFACTURE, PREPARATION, AND APPLICATION. MANUFACTURE OF ANIMAL GLUE.}

The process of making animal glue is briefly as follows: The stock is washed and treated to remove dirt and grease, and then boiled to convert the glue-forming substances into a glue solution. This solution is concentrated by evaporation until it will form a jelly on cooling. The jelly is then cut into various forms and dried.

There are many details and variations which depend upon the kind of stock used and the plant in which the glue is made, and which affect more or less the character of the resultant glue. Bones are sometimes boiled without first removing either dirt or grease. This practice 
ANNUAI REPORT NATIONAL ADVISORY COMMITTEE FOR AERONAUTIOS.

naturally fails to produce a high-quality glue. Bones may or may not be treated with acid to remove the calcium salts before cooking; and this also influences the glue quality. In cooking, the temperature and time must be carefully watched, as over-cooking may materially reduce the strength of the glue. The stock is usually boiled with fresh water several times. The first boiling or first run gives the best glue, and each later a weaker.

As the solution of glue from the boiling kettles is too weak to form a jelly which can be handled, it must be concentrated. This is done by boiling off the water in vacuum dryers until the percentage of glue in the solution is high enough to make a firm jelly on cooling. If the temperatore rises too high during the concentrating process the quality of the glue may be lowered.

When sufficiently concentrated the glue solution is cooled by refrigeration, either after being run into pans or as it runs upon a traveling belt. As it cools it forms a jelly firm enough to handle. The jelly in the pans is removed, sliced with wires or a knife, and placed upon sereens to dry. If a belt is used the jelly is formed in a continuous sheet, which is cut into sections and placed on screens as it travels along. The screens are then placed in a drying chamber and left until the glue is dry. Glue may be easily injured during the drying process if the temperature conditions are not properly controlled.

'The form of the glue when dry depends upon the shape in which it was placed upon the screens. If carefully sliced to the proper thickness regularly shaped cakes will be formed. The sheet glue from the belt breaks into thin irregularly shaped pieces as it comes from the drying nets. This is commonly run through a machine to break it into smaller pieces, in which shape it is shipped as flake glue. Other forms of glue are also made, and any of the forms may be subsequently ground and sold as ground glue.

Sometimes mineral matter such as barium sulphate, white lead, chalk, zinc oxide or whiting is added to'the glue after it has been concentrated, but before it is cooled. This gives it a light color and makes it opaque, which is a feature desired by some consumers.

Nominal grades can not be relied upon when purchasing aninal glue for high-class work. $I_{t} t$ is necessary for the purchaser who buys on bids to specify his requirements and then provide means to insure that the glue furnished by the manufacturer is up to these requirements. The variety in character, color, form, strength, and other characteristies of animal glues is almost without limit. A system of classification, based chiefly on the jelly strength, was devised a long time ago by Peter Cooper. By means of this system it is possible to group the great variety of glues into a relatively small number of classes or grades. The grades established by Cooper were designated, beginning with the strongest, A extra, 1 extra, $1,1 \mathrm{X}, 1 \frac{1}{4}, 1 \frac{3}{3}, 1 \frac{1}{2}$, $15,1 \frac{3}{4}, 17,2$. There are now on the market glues stronger than A extra, and glues weaker than 2, for which there is no standard Peter Cooper grade. This system of grading, however, appears to be but little used to-day by manufacturers, except occasionally for comparative purposes. Each manufacturer has his own system of grading, which he keeps more or less secret. and to the general buying public the grades mean little or nothing. It is sometimes claimed, also, that the Peter Cooper gxades of to-day are not the same as those originally established.

\section{MIXING AND APPLICATION OF ANIMAL GLUE.}

In using animal glue various precautions must be observed if satisfactory results are to be obtained. By improper use a very high-grade glue may be made to give poor joints. It is important, first, to find out the right proportion of glue and water to use in order to get the best results with the wood that is being employed and the conditions under which the work is being done. This is largely a matter of experience, but it can also be determined by strength tests. When the right proportions have been decided upon, they should be strictly adhered to thereafter, and the glue and water should be weighed out when making up a new batch of glue rather than measured or guessed at. Clean, cold water should be used, and the mixture thoroughly stirred to prevent lumps. It should then stand in a cool place until the glue is 
thoronghly water-soaked and softened. This may take only an hour or two, or it may take all night, depending upon the size of the glue particles. It should then be melted over a water bath. The temperature should not be allowed to go higher than about $150^{\circ} \mathrm{F}$; ; high temperatures and long-continued heating reduce the strength of the glue. The glue pot should be kept covered as much as possible in order to prevent the formation of a skin or scum over the surface of the glue.

The room in which the glue is used should be as warm as possible without causing too much discomfort to the workman, and it should be free from drafts. In a cold drafty room the glue cools too quickly and may set before the joint has been put into the clamps. The result is a weak joint. It is also considered good practice to warm the wood before applying the glue, but it should not be heated long enough to cause an appreciable moisture change. Wood should never be glued when it is colder than room temperature, and, of course, only thoroughly seasoned wood should be used. Since high-strength animal glues set so quickly on cooling, they should be applied and the joints clamped as quickly as is consistent with good workmanship.

In clamping, the "pressure should be evenly distributed over the joint so that the faces will be in contact at all points. The amount of pressure to give the best results is a question which has never been definitely settled. Apparently no tests have yet been made to show the best pressure to use on edge or flat grain joints. In gluing veneers it is necessary to use high pressures in order to flatten out the irregularities of the laminations. Pressures as high as 150 pounds per square inch are sometimes used, but it is not established that such high pressures are necessary or desirable. Too much pressure must not be used in gluing surfaced wood, as the glue may be pressed out too completely from the joint, produeing a so-called starved joint.

Strict cleanliness of glue pots and apparatus and of the floors and tables of the glue room should be observed. Old glue soon becomes foul and affords a breeding place for the bacteria which cause decomposition. The fresh glue is, therefore, in constant danger of becoming contaminated. Glue pots and brushes should be washed after every day's work. The brushes will remain sweet if kept when not in use in a weak solution of carbolic acid. Glue enough for a day's run only should be mixed at one time, so that mixed glue will not have to be held over from one day to another. If these sanitary precautions are not observed, poor joints may result.

\section{STRENGTH OF ANIMAL GLUE.}

The highest grades of animal glue are the strongest glues used in woodworking. Their strength is greater than that of the woods they are used upon, and when they are properly applied they are exceedingly reliable, so long as they are not exposed to moisture. The certified glue used in propeller manufacture was sufficiently strong for the highest type of woodworking, but still higher grades of glue are obtainable. The certified glues were required to have an average shearing strength ${ }^{1}$ of 2,400 pounds per square inch, with a minimum of not less than 2,200 pounds per square inch. Most of them, however, actually showed an average shearing strength of between 2,500 and 3,000 pounds per square inch.

The shearing strength of the lower grades of animal glue, such as $1 \frac{1}{6}$ and less, is somewhat lower, but by careful application fairly high values can be obtained from them.

The water-resistance of animal glue is low; but the high grades, which have high jelly strength will stand dampness for longer periods than the low grades, which have low jelly strength.

\section{LIST OF REFERENCES.}

In a brief discussion of this nature it is not possible to cover thoroughly all the points touched upon, or even to mention many things which the glue user or inspector should linow. Those who wish a fuller knowledge of the subject are referred to the following publications:

$135573-19-2$ 
BOOKS.

Agglutinants of all kinds and for all purposes. By H. C. Standage. Pp, 207. D. Van Nostrand Co., New York, 1907, $\$ 3.50$.

Glue gelatine, etc. By F. Dawidowsky. Pp. 282, illus. H. C. Baird Co., Philadelphia, Pa., 1905, $\$ 3$.

Glues and gelatines. By R. L. Fernbach. Pp. 200, illus. D. Van Nostrand Go., New York, 1907. Disensses the manufacture, classification, testing, and analyses of glues and gelatines, and gives information on substitutes. $\$ 3$.

Glue and glue testing. By Samuel Rideal, Pp. 144, illus. Scott, Greenwood \& Son, London, 1901, Discusses the manufacture, testing, and use of glues, especially the chemical side. $\$ 4$.

The glue book. By J. A. Taggart. Pp. 85, illus. The Republican Publishing Co., Hamilton, Ohio, 1913. i)iscusses "how to select, prepare, and use glue." $\$ 1$.

Glue handling. By Friman Kahrs. Pp. 128, illus. Alliance Printing Co., New York, $1906 . \$ 1$.

\section{JOURNAL ARTICLES.}

Specifications and tests of glue. By 0 . Linder and J. O. Frost. In the proceedings of the American Society for Testing Materials, 1914, Part 2, pp. 509 to 519 . Gives the results of tests of cabinet glue.

A study of various tests upon glue. By A. H. Gill. In the Journal of Industrial and Engineering Chemistry, 1915, vol. 7, pp. 102 to 106 . Gives the results of tests made at the Massachusettis Institute of Technology. Guve for use on airplanes. By R. A. Houseman. In the Journal of Industrial and Angineering Chemistry, 1917, vol. 9, pp. 359 to 360 . Republished in Aviation, July 1, 1917, p. 462.

The građing and use of glues and gelatine. By Jerome Alexander. In the Journal of the Society of Chemical Industry, 1906, vol. 25 , pp. 158 to 161 .

\section{LIQUID GLUES-THEIR MANUFACTURE, PROPERTIES, AND USES.}

Liquid glues vary over an exceedingly wide range, not only in their appearance and properties but also in their chemical constituency. Most of them are manufactured from the heads, bones, swimming bladders, and other offal from fish.

The process is somewhat similar to that used in the manufacture of animal glues. The offal is thoroughly washed with water and then discharged into extractors and digested with live steam. After digestion the liquid is drawn off and allowed to stand, following which the upper oily layer is removed. The lower gluey solution is then clarified with alum, filtered, concentrated in open vats, and bleached with sulphur dioxide. The resulting glue is a lightbrown viscous liquid of extremely disagreeable odor. It is sometimes treated with sodium phosphate or perfumed in order to make the odor less offensive. Dextrine, certain gums and resins, starch, casein, rubber, and bitumen also find occasional use in the manufacture of liquid glues.

A few liquid glues are made with animal glue as a base by treating the latter with a chemical agent that destroys the power of the glue to form a jelly, and by mixing it with a thinner which evaporates when the glue is used and permits it to set.

A good liquid glue has certain advantages. It can be used cold and spread without any preparation whatever. On the other hand, it is not generally so strong as high-grade animal or casein glues, is more expensive, and not so widely marketed. Its use in airplanes is confined to repair work and well-protected parts. The majority of purchasers have no way of knowing in advance how satisfactory a liquid glue will prove to be. Some preliminary studies made at the Forest Products Laboratory indieated that the strength of liquid glue varies with its "body" or viscosity. As a rule, a thick viscous glue will give high strength and vice verss. The body or viscosity is also important because it influences the amount of glue which may be maintained in a joint when pressing. A thin glue will spread a larger area, but the layer on the wood will be so thin that there is danger of squeezing it out under pressure and producing a weak, or "starved," joint. Other qualities desirable in liquid glues are ability to dry and set rapidly when spread on wood surfaces, and to remain liquid while in the container and over ordinary ranges of temperature. 


\section{CASEIN GLUES-ThEIR MANUFACTURE, PREPARATION, AND APPLICATION.}

One of the many direct results of the war has been the introduction of casein glues into the woodworking industries of this country. Previously these glues had been used in Europe to a limited extent in bookbinding and cabinet work, but their production on a large scale was unknown. In the United States the use of casein glues is more recent and their development has been more rapid than in Europe. At the beginning of 1918 only one plant in this country was manufacturing a water-resistant casein glue. With our entrance into the war the demand of the Army and Navy for waterproof ply-wood enormously increased the production, so that by the latter part of 1918 four different companies were manufacturing casein waterresistant glues and the Forest Products Laboratory had developed several formulas for making them.

\section{TYPES OF CASEIN GLUES.}

There are, in general, two types of casein glues which for convenience may be designated as prepared glues and wet-mix glues. In the former, the glue components are mixed dry; while in the latter, the ingredients are added separately and at different times during the mixing process. Casein glues on the market are of the dry-mix type; that is, they are prepared and shipped ready to add to water. The Forest Products Laboratory has done a large amount of work in developing casein glues, and some of the best formulas are of the wet-mix type.

\section{MANUFACTURE OF CASEIN.}

The principal constituent of all cascin glues is casein, a product obtained from mill. When milk sours naturally, casein is precipitated and appears as "curd." When produced in this way it is known as self-soured or naturally soured casein. Various acids may be added to the milk to precipitate the casein, the principal ones used being hydrochloric (muriatic) and sulphuric. Rennet is also used to some extent as a precipitating agent.

The usual steps in the production of casein are: (1) Removal of fat in the form of cream from the milk, which is usually accomplished by means of a separator; (2) precipitation of the casein; (3) washing to remove the acid and other impurities; (4) drying; and (5) grinding to a powder. The care used in these various steps of manufacture has a large effect upon the glue-making properties of the casein.

The principal requirements of casein to make it desirable for glue making are: (1) A low percentage of impurities such as acid, moisture, and fat; (2) freedom from sour odors; (3) clearness and uniformity of color; and (4) fineness of particles. By grinding a casein to fine particles a minimum of time is required in the mixing and a more uniform glue is obtained. A casein ground to pass through a screen of from 50 to 60 meshes to the inch will give good results.

\section{MANUFACTURE OF GLUE.}

To produce glue, casein is mixed with other ingredients, the chief of which are lime and water. These three constituents alone will give a glue of good water-resistant properties, but of short life. Other ingredients are, therefore, added to increase the working life and the water resistance and to improve the other qualities of the glue. Caustic soda, sodium fluoride, and sodium silicate are used in some patented formulas. They all lengthen the life of the glue, and sodium fluoride probably gives the glue antiseptic properties. Still other ingredients are added to give the glue some particularly desired property. Oils are usually added to the dry-mix glue to prevent dusting in handling the glue. Formulas vary, therefore, not only in materials used but also in the proportions of different ingredients. 
Several formulas for mixing casein glues have been developed at the Forest Products Laboratory. One of the best of these, with a discussion of the method of mixing and a description of materials required, follows.

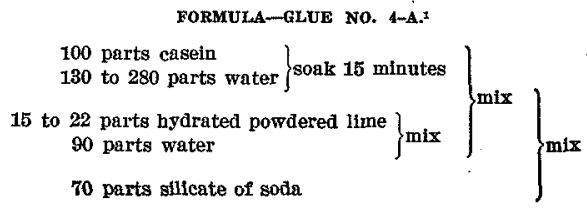

\section{METFOD OF MIXING.}

The proper quantity of water is introduced into the glue pot, and the mixing blade is brought into action at a speed corresponding to about 50 or 60 revolutions per minute. The stirring is allowed to continue during the addition of the casein to the water and for a few minutes thereafter until the mixture becomes mush-like in consistency through the absorption of the free water by the casein. The blade is then stopped and the mixture allowed to soak.

After a period of 15 minutes the soaking is considered complete and the mixing blade is again brought into action. The lime-water mixture is now added and two or three minutes later the liquid silicate of soda is introduced.

The mixing is allowed to continue for from 20 minutes to one-half hour after the addition of the silicate of soda, whereupon a smooth, freely flowing mixture, of uniform texture and free from lumps, should be produced.

Usually some experience in the mixing of this glue is necessary before satisfactory results can be expected, and it is advisable to have a new operator witness an actual demonstration. This is due to the fact that no precise quantity of water can be prescribed because of the variation in the water-absorbing qualities of different caseins. The criterion of whether or not the proper quantity of soaking water has been added is the viscosity of the finished (mixed) glue. If its consistency is too thin, an excess of water beyond that required has been used, and it is best to reject the batch and try again. Similarly, if the consistency is too thick and heavy, an insufficient quantity of water has been used. The water required for various types of casein lies in the following ranges:

Lactic-acid casein
Sulphuric-acid caseln-a
Hydrochloric-acid casein
Rennet casein
130 to 170 parts water 170 to 220 parts water 280 parts water

DESCRTPYYN OF MATMETALS.

Casein.-It is essential that the casein be of a reasonably pure grade, carefully manufactured, free from offensive odors, not of a dark yellow, dirty, or other objectionable color, and low in fat, as well as in free acid. It should be fine enough to pass through a 60 -mesh sieve.

Lime.-A high calcium lime gives satisfactory results, but limes containing a relatively large amount of magnesia can be employed if a quantity sufficient to give the required calcium hydroxide content be used. It can be prepared for use by adding just enough water to fresh quicklime to cause it to slack to a powder. It should then be made fine enough to pass entirely through a 60-mesh sieve. Commercial powdered hydrated limes are also suitable.

Siticate of soda.-The silicate of soda is in liquid form and corresponds to the grade which appears on the market for preserving eggs or for adhesive purposes. The various samples which have given satisfactory results at this laboratory have had analyses included within the following ranges:

2 8. S. patent No, 1291398 on this process has been granted to Samuel Butterman, of the Forest Products Laboratory, and assigned to the United States Government. 


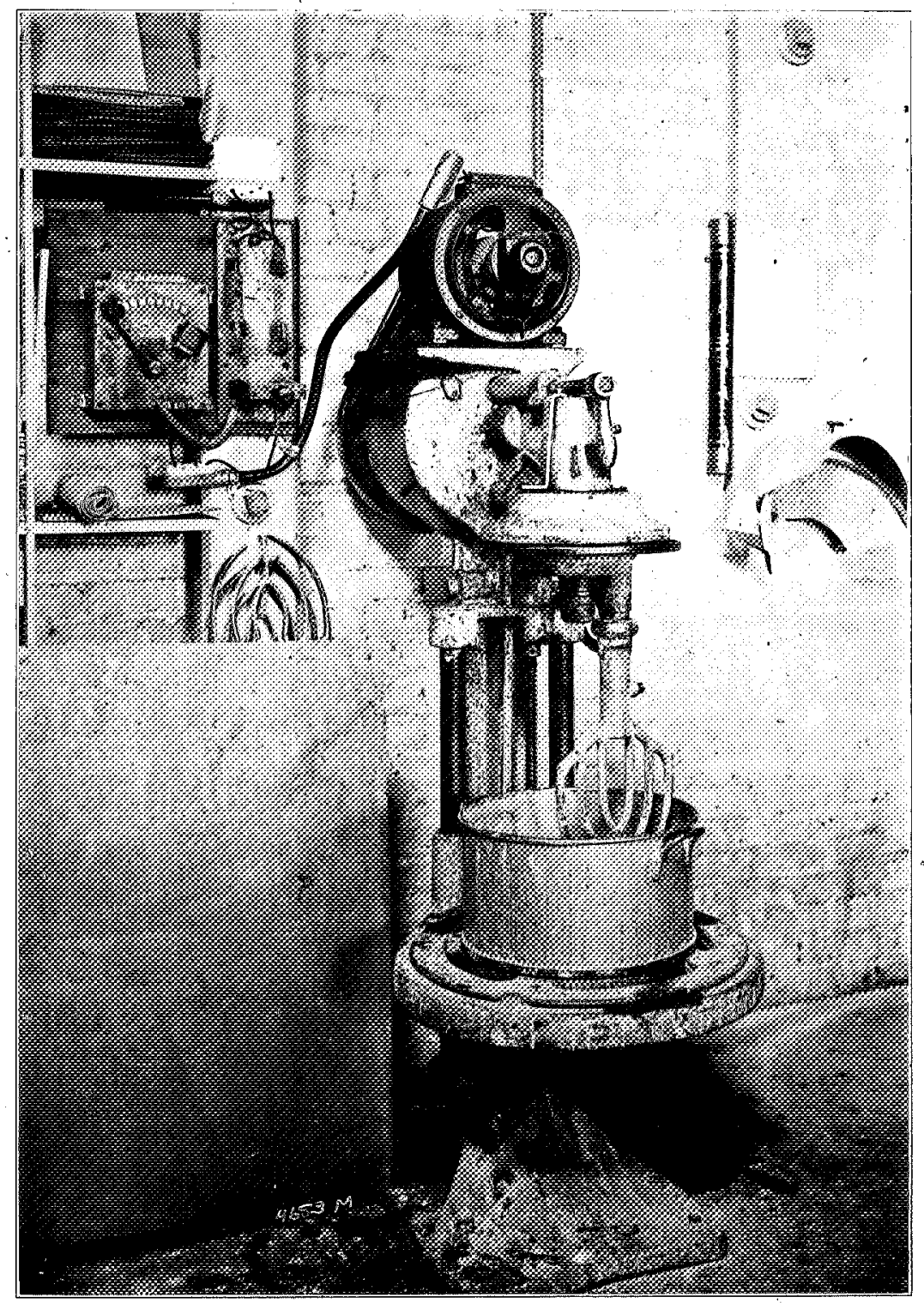

PLATE I.-TYPE OF CAKE AND EGG MIXER USED FOR MIXING CASEIN GLUE. 
Speclfic gravity

1.38 to 1.42

Density (Baumé scale)

$40.31^{\circ}$ to $42.96^{\circ}$

Sodium oxide

9.38 to 9.88

Silica

31.41 to 32.38

This formula gives a glue of considerable water resistance. It has formed the basis for a large part of the later experimental work on casein glues at the Forest Products Laboratory. By modifying the proportions of materials and adding still other components glues of very desirable qualities are obtained. The degree of water-resistance and the workable life of the glue after mixing can be greatly varied. This property of the wet-mix glues, namely the variation of the components to attain glues of special qualities is one of the chief advantages over the dry-mix type. The dry-mix glues on the other hand require less technical knowledge on the part of the user than do the wet-mix type.

PREPaRED GaserN gLUES.

Commercial casein water-resistant glues are of the dry-mix type, of which four are at present on the market. They are made by secret formulas and the details of the method of their manufacture are not public. Directions for mixing these glues are furnished by the manufacturers and should generally be followed by the user. The principal points to be observed in the mixing of prepared casein glues are:

1. A thorough mixing of the dry glue from ench or all containers before adding to the water. This is advisable on account of the segregation of ingredients of different specific gravities which may occur during shipment from the factory to the consuming plant. Sifting is not advisable, as it may remove from the glue some essential component.

2. Proportions of glue and water should always be weighed, not measured.

3. The glue should be added slowly to the water accompanied by vigorous agitation in order to avoid a lumpy mixture.

4. After the glue is well mixed into the water, the stirring should continue more slowly until all particles are thoroughly dissolved and the glue appears of a smooth, creamy consistency.

5. The desired consistency of the glue should be attained during the mixing and no attempt should be made to thin the glue should it become too thick in use. It should be mixed only as fast as it is being used.

The proportions of dry glue and water should, in general, be as directed by the manufacturer. However, the exact proportions will vary with (1) different glues, (2) different shipments of the same glue, and (3) the kind of work for which the glue is to be used. Only average proportions can be stipulated by the manufacturer; and the operator, in order to obtain satisfactory consistencies, may find it necessary at times to vary from the average proportions specified.

TYPE OF MTXYR.

The ordinary types of mixers used for animal and vegetable glues are not well adapted to casein glues. The prime requisites for a mixer for these glues are: (1) Rapid agitation and, preferably, different speeds of the paddle; $(2)$ a glue pot that can be readily cleaned $\longrightarrow$ preferably one that can be detached from the machine itself; and (3) a glue pot of metal that will not corrode under the action of alkali. The mixing pot should not be of brass, copper, or aluminum, as the alkali usually present in casein glues will attack these metals. No provision need bo made for heating, as casein glues must not be heated. A mixer that has proved satisfactory at the Forest Products Laboratory is a power calke-dough mixer of the type used by bakers. (See Plate I.) The machine has a double-acting paddle and may be operated at three different speeds. Some glue manufacturers have devised inexpensive machines which do good work and which embody the essential points of thorough agitation and ease of cleaning the mixing bowl. 


\section{APPLICATION OF GLUE.}

Casein glue may be applied to the wood either by hand or with a machine spreader. In applying by hand, a wire brush or a metal scraper gives good results. If the glve is to be spread on irregular joints with a bristle brush a somewhat thinner mixture may have to be used. The ordinary corrugated roll type of machine spreader works well. Enough glue should be spread to cover both surfaces of the joint and a small amount should squeeze out from the joints when pressure is applied.

The working life of casein glues varies from a few to many hours. A glue of moderate consistency should have a life of at least four or five hours, and glues may be made which will last for many hours. The fitness of a glue for use should be judged by its consistency; ordinarily, as long as it can be uniformly spread, a good glue will give good results. The time that may elapse between the spreading of the glue upon the wood and the pressing will depend upon several factors, chief of which are: (1) The moisture content of the wood; (2) the consistency of the glue; (3) the kind of wood; (4) the quantity of glue applied, and (5) the temperature of the wood and glue. The time should be correspondingly reduced if the wood is of an open, porous nature and of a low moisture content, or if a thin spread or a thick, heary glue is used. A high temperature causes the moisture to disappear more rapidly from the glue layer and also hastens the setting of the glue. In general, the pressure should be applied while the glue is yet in a wet condition, in order to obtain contact between the uncoated wood and the glue layer. If the glue becomes too thick, poor contact will result. In most cases, if pressure is applied within ten to fifteen minutes good results will be obtained. Under other conditions a longer time may elapse.

\section{PRESSURE.}

Sufficient pressure should be applied to bring the layers of wood into close contact with the glue. A pressure of from 75 to 100 pounds per square inch is usially considered ample. This will necessarily vary with the consistency of the glue and the character of the material being joined. Greater pressures are necessary for irregularly surfaced material and thick glue mixtures than with the opposite conditions. The time under pressure may vary from a halfhour to a much longer period. Good joints have been obtained by pressing for only one-half hour. A longer period will probably give better results. Where it is convenient retaining in clamps over night is generally practiced.

After the material is removed from the press, it should preferably be allowed to condition before being finished. The time required for conditioning will depend upon the size of the stock, the moisture content of the material before gluing, the condition under which it is seasoned and the requirements of the finished product. A uniform moisture content of approximately that desired in the finished piece should prevail in the material before it is put through the finishing process.

\section{STORAGE OF CASEIN GLUES.}

Dry casein and casein glues will keep for a long time if stored under proper conditions. When bought in large quantities they should be stored in a cool, dry place, as excessive moisture and high temperatures cause deterioration.

\section{STRENGTH AND WATER-RESISTANCE.}

Casein glues, when properly mixed and applied, have good strength and water-resistant properties. These qualities are well demonstrated by the tests imposed on plywood manufactured for use in airplanes. To be accepted samples were required to show no separation of the plies after boiling in water for eight hours or soaking in cold water for ten days. For shearing strength in plywood the requirements were at least 150 pounds per square inch, but most of the plywood tested at the Forest Products Laboratory showed values considerably higher than this minimum requirement. Tested wet after several days' soaking, cassin glues 
commonly have from 20 to 40 per cent of their dry plywood shear strength. If, however, the glue is redried after being soaked, the original strength of the glue is very largely recovered.

As a joint glue, casein is as strong as the wood of practically all of our common species. Tested on blocks of maple with the grain running in the same direction, shearing strengths are commonly obtained ranging from 2,000 to 2,500 pounds per square inch, with a large percentage of failures in the wood. The progress which is being made in developing new formulas and improving the methods of manufacture is constantly increasing the strength and waterresistance which can reasonably be demanded of casein glues.

\section{REFERENCES ON CASEIN AND CASEIN GLUES.}

hOOKS ON CHEMISTRY OF CASEIN.

The physical chemistry of the proteins. By T. B. Robertson. k'p. 483. Juongutans, Green \& Co., New York, 1918.

General characteristies of proteins. By S. B. Schryver. Pp. 86. Longmans, Green \& Co., London, 1909.

Chemistry of the proteids. By Gustav Mann. Pp. 606. Macmillan \& Co., London, 1906.

Chemical constitution of the proteids. By I. H. A. Plimmer. Pp. 165, illus. Longmans, Green \& Co., New York, 1917.

Casein and its primary cleavage products. By $R$. $\mathrm{A}$. Chittenden and $H$. M. Painter. In the transactions of the Connecticut Academy of Arts and Sclences, 1888, vol. 7, pp. 362-405.

Caseoses, casein, dyspeptone, and casein peptone. By R. H. Chittenden. In the transactions of the Connecticut Academy of Arts and Sciences, 1888, vol. 8, pp. 66-105.

Dairy chemistry. By H. D. Richmond. Pp. 434, illus. J. B. Lippincott Co., Philadelphia, Pa., 1914.

Commercial organic analysis. By A. H. Allen. 4 vols., illus. J. \& A. Churchill, I.ondon, 1898-1907.

Dictionary of applied chemistry. By T. E. Thorpe. 5 vols., illus. Longmans, Green \& Co., New York, 1912-13.

A textbook of physiological chemistry. By O. Hammarsten, translated by J. A. Mandel, Pp. 628. J, Wiley \& Son, New Xork, 1900.

Practical physiological chemistry. By P. B. Hawk. Pp. 661, illus. P. Blackiston's Son \& Co., Philadelphia, Pa., 1018.

Industrial chemistry. By A. Rogers and A. B. Aubert. Pp. 854, jllus. D. Van Nostrand Co., New York, 1912.

Treatise on general and industrial inorganic chemistry. By Ettole Molinari. 3d Italian edition tr. by E. Feilmann. Pp. 704. P. Blackiston's Son \& Co., Philadelphia, Pa., 1912.

Casein, its preparation and technical utilization. By R. Scherer. Pp. 182, illus. Scott Greenwood \& Son, london, 1911.

The manufacture of casein from buttermilk or skim milk. By A. O. Dahlberg. Pp. 22, illus. U. S. Department of Agriculture Bulletin No. 661. U. S. Department of Agriculture, Washington, D. C., 1018.

Agglutinants of all kinds, for all purposes, By H. C. Standage. Pp. 267. D. Van Nostrand Co., New Yorl, 1907. \$3.50. Contains information on casein glues.

\section{ARTICLES ON MANUFACTURE AND USE OF CASEIN.}

Colloid chemistry of casein, etc. By H. B. Stoclss, In Report of British Association for the Advancement of Science, pp. $65-97,1917$.

Casein, its utilization in the paper industry. In World's Paper Trade Review, vol. 46, pp. 281-657, 1906.

Casein and its applications. By Richardson. In the Journal of the Society of Dyers and Colorists. Vol. 25, p. $48,1909$.

Comments from Copenhagen; casein production. In New York Produce Review and American Creameries. Vol. 31, No. 1, p. 12, October 26, 1910.

\section{Patent literature on Casein glues.}

U. S. Patent 838785 Isaacs, 1906.

845790 Isaacs, 1907.

848746 Isaacs, 1907 .

84579.1 Isaaes, 1907.

848277 Isaaes, 1907 .

1192783 Isaacs, 1916.

183024 Ross.

21744 Gardner, 1896

609200 Hall, 1896 (Reissue 11,811, 1900).

1291396 Butterman, 1918.

1310706 Lindauer, 1918.
German Patents 116355 Wenck, 1900.

154289 Jeromins, 1904

60156 Pick, 1891. 
A large number of articles have been published on the chemical properties of pure casein. They can be located through Chemical Abstracts. Most of the articles published in English have appeared in the following journals:

Journal of Biological Chemistry.

Journal of Physical Chemistry.

Journal of the American Chemical Society.

Technical Bulletins of the New York Agricultural Experiment Station.

\section{BLOOD ALBUMIN GLUES-THEIR MANUFACTURE, PREPARATION AND APPLI- CATION.}

The use of blood albumin glue is comparatively new in this country. Previous to our entry into the war, a few manufacturing plants had their own secret formulas and were using them in the preparation of glue. But the demand for water-resistant plywood for military purposes caused a marked increase in the production of all kinds of waterproof glues, both casein and blood albumin. During the period of the war, the Forest Products Laboratory developed several formulas for blood albumin glues and worked out a method of gluing very thin veneer by a dry blood glue process.

\section{WET GLUE PROCESS.}

Prepared blood albumin glues are not offered on the market, chiefly on account of the decrease in solubility of the albumin with age. They are, therefore, mixed at the time of using. The glue may be made either from the fresh blood of slaughtered animals or from black soluble blood albumin obtained by processing the fresh blood. To make the use of fresh blood feasible, the supply must be readily accessible to the place of manufacture, inasmuch as rapid decomposition takes place and renders it unsatisfactory for glue purposes. Unless utilized at once it must therefore be treated with a preservative or converted into a dried soluble form. The dried soluble albumin is the form from which the glue is generally made, and is obtained by subjecting the fresh blood to a process for removing the fibrin and part of the red corpuscles and then evaporating to dryness at a temperature below the coagulating point of the albumin, which is approximately $160^{\circ} \mathrm{F}$.

PREPaRation of GLUE.

(Forest Products Laboratory Kethod.)

In order to put the dried albumin into solution, it is necessary to allow it to soak for some time before stirring. It is advisable to add water at about room temperature to the albumin and allow it to stand two hours or more before stirring. It should then be agitated until it is of uniform consistency. If coarse particles of insoluble material occur, the mixture may be strained through a screen of about 30 meshes to the inch. The dried albumin always contains some insoluble material and becomes more and more insoluble with age.

A mixture of blood albumin and water makes a glue with a considerable degree of adhesiveness, but it may be improved by the addition of other materials. The basic blood albumin glue formula ${ }^{1}$ for the wet glue process worked out at the Forest Products Laboratory consists of:
6 parts of biack soluble blood albumin ( 90 per cent solubility).
11 parts of water at about $80^{\circ} \mathrm{F}$.
1 part of ammonium hydroxide (sp. gr. 0.90 ).
1 part hydrated lime (from 2 to 3 per cent of the weight of albumin).

After the blood has been put in solution, the ammonia is added while stirring the mixture slowly. The lime is then added in the form of a thick cream, and agitation should be continued slowly for a few minutes. Care should be exercised in the use of the lime, inasmuch as a small excess will cause the mixture to thicken and become a jellylike mass. The glue should be of 
moderate consistency when mixed and should be suitable for use for several hours. The exact proportions of albumin and water may be varied to produce a glue of greater or less consistency or to suit an albumin of different solubility than that specified.

\section{APPLICATION OF GLUE.}

The glue may be applied to the wood either with a bristle brush or with a glue spreader. If the spreader is used it should be run only when actually coating the wood, as otherwise the glue may become foamy.

$$
\text { - PRessnge. }
$$

To set the glue, a minimum temperature of approximately $160^{\circ} \mathrm{F}$. is necessary, which causes the blood to coagulate. When thoroughly coagulated, the glue can not again be dissolved in water. The heat is conveniently applied to the wood by pressing between the hot platens of a hydraulic press. In order to reduce the time required in the press and thus increase its capacity, it is customary to use a temperature of from 200 to $220^{\circ} \mathrm{F}$. Excessively high temperatures, however, tarn the moisture in the glue and wood to steam and are likely to produce steam pockets or blisters between the plies of wood. A pressure of from 50 to 100 pounds per square inch is desirable. The time required for pressing depends upon the thickness of the plies, the number of panels in the press, and the temperature of the plates. With a temperature of $212^{\circ} \mathrm{F}$. three minutes are sufficient for one three-ply panel with $\frac{1}{16}$-inch face plies. The necessary length of time naturally increases with an increase in thickness of material.

Blood albumin glue is used in plywood construction chiefly. It may, however, be used for thicker material. For thick blocks it is necassary to apply pressure and maintain it by the use of retaining clamps, and then subject the material in a kiln or hot room to a temperature sufficient to set the glue.

Blood albumin glue is highly water-resistant, surpassing in this respect the present casein glues. It retains its shearing strength to a remarkable degree after soaking or boiling, giving from 50 to 75 per cent of the dry strength. It is known to possess strength sufficient for joint work, although, on account of the difficulty of setting the glue, it is generally considered impractical for this purpose.

\section{PRECAUTIONS IN THE USE OF BLOOD ALBUMTN GLUE.}

Several precautions should be observed in mixing and applying blood albumin glue.

1. Weigh out all constituents; do not measure them.

2. Add cold water to blood albumin and do not heat mixture.

3. Do not stir blood until it has soaked for from one to two hours.

4. Avoid excessive stirring of the glue or agitation on the spreader, since this produces foamy glue.

5. Load press and apply pressure quickly to prevent coagulating the blood before pressure is secured.

6. Pressures ranging from 50 to 1,00 pounds per square inch are advisable, depending upon the glue consistency, nature of wood, etc.

7. Excessively high temperatures of the platens of the press produce steam, causing blisters. A range of 200 to $212^{\circ} \mathrm{F}$. is advisable.

8. Panels should be left in the press until the heat has penetrated so as to raise all parts to at least $160^{\circ} \mathrm{F}$.

9. Be careful not to use an excessive amount of lime or a strongly alkaline water.

\section{DRY GLUE PROCESS FOR THIN VENEER.}

Gluing thin veneer ranging from $\frac{1}{30}$ to $\frac{1}{125}$ of an inch into a very thin panel has always been extremely difficult. The principal causes of trouble have been penetration of glue through the face plies and excessive swelling of the thin veneer due to the rapid absorption of water 
from the wet glue, producing overlaps, curling, and wrinkling. These troubles have made the manufacture of very thin plywood a very difficult and expensive process. To overcome these difficulties, a method of gluing very thin veneer was worked out at the Forest Products Laboratory in cooperation with the Bureau of Aircraft Production for the construction of experimental material, particularly for airplane wing covering.

A blood albumin glue was developed which when dried could be used successfully to glue veneer 1 of an inch in thickness, or even thinner. The glue mixture used in this process varies from the standard formula given above principally in the addition of a substance which makes the glue hygroscopic, or capable of attracting and retaining moisture, sufficiently to give a contact with wood.

\section{Preparation of Glue layer.}

The principal steps in the manufacture of the glue layer are: (1) Mixing the glue, (2) coating on tissue paper or cloth, and (3) drying.

To obtain good results, the glue must be mixed thin and be free from lumps or undissolved particles. Straining through a sieve is absolutely necessary in this case.

The first machine used for coating this glue on the paper and drying was devised and built at the Forest Products Laboratory. The process was later introduced into a commercial paper coating plant, an improved form of the machine for drying and coating was installed, and the product can now be produced on a commercial basis.

A thin, porous tissue paper is used for coating and is placed in a machine geared to run it through the glue bath at a rate of approximately 1 foot per minute. The tissue paper passes over a roller in the glue bath, and upward into a drying chamber to a worm roller upon which there are strips of felt to prevent it from wrinkling. It then passes over a third rollex and through pinch rolls to a final dry roll. Cloth may be used as the medium upon which the glue is dried and then be made to serve as one ply in panel construction.

\section{GLUING PROCESS.}

In manufacturing plywood with the glue, sheets of it are placed between the plies of the wood and pressed in a hot press. A pressure of from 150 to 200 pounds per square inch is necessary in order to bring about good contact between the glue layer and the wood. If the moisture of the veneer is low, the water-resistant properties of the plywood may be increased by a slight sprinkling or sponging of the veneer immediately before placing in the press.

\section{ADVANTAGES OF THIS PROCESS.}

This form of glue has advantages over the wet glue process, chief of which are:

1. Veneer as thin as one-one hundred and twenty-fifth of an inch may be glued up sticcessfully.

2. Overlaps, wrinkling, open joints, etc., are overcome.

3. Gluing with the addition of little or no moisture overcomes cupping and twisting of panels.

4. Drying of plywood is largely eliminated.

5. Subsequent trouble in checking of veneer in drying is eliminated.

6. Glue is always ready for use and keeps for a long time.

7. It can probably be used more rapidly and with less labor than the wet glue process.

8. No spreader is required.

\section{VEGETABLE GLUE-MANUFACTURE AND USE.}

The term vegetable glue is considered in the woodworking industries to mean glue made from starch. There are other adhesives which are derived from vegetable sources, but these are not commonly used in woodworking. Vegetable glue is usually made from cassava starch. 
which appears to be especially adapted for the purposes, but others such as corn starch or potato starch are sometimes used'alone or mixed with cassava starch. Vegetable glue is not used in airplane manufacture but is here discussed briefly as a matter of interest.

In one of the vegetable glues now on the market, the cassava starch is first treated to reduce its water absorbing power. This is ordinarily accomplished by heating the starch with an equal weight of water to $130^{\circ} \mathrm{F}$., stirring, and then adding strong sulphuric aoid to the mixture. Stirring is then continued for several hours after which the acid is neutralized with an alkali and the mixture finally drained and dried. It is sold in this form as a starch base for the preparation of vegetable glue by the addition of caustic soda. It is customary for the manufacturer to sell the starch base and the caustic on the basis of a definite price per pound for "dry glue."

In preparing the glue for use, the starch is usually placed in a jacketed mixer so that it can be heated and stirred when the water and caustic soda are added. About one hour's stirring is necessary to complete the mixing. The glue can be prepared without heat if a higher percentage of caustic is used.

The resulting product is a viscous, translucent material which is used cold and which will keep for many days without deterioration. On account of its stiff consistency mechanical spreaders are required to apply the glue. It has not been found suitable, therefore, for irregularly shaped joints, which require hand spreading. It is pressed in cold presses in the same manner as casein glue.

There are other prepared vegetable glues on the market which, up to the present time have not been so widely used as the one just discussed. These have various starches for their bases and are manufactured by processes which are more or less secret. It is also possible to make vegetable glue of good strength directly from the unprepared starch, with or without the use of caustic soda or other chemicals.

This method and the methods which vary the amount of caustic used promise to be of value in eliminating the objection to vegetable glue occasioned by staining, which often occurs in gluing fancy furmiture veneers, such as one-twenty-eighth inch birdseye maple and mahogany. The reduction of the amount of alkali in the glue will reduce the danger of staining, but will shorten the life. A vegetable glue made in this way without caustic will, however, remain workable for 24 hours.

The status of the various vegetable glues is more or less involved in patent litigation, and in using any of them the user should be thoroughly informed on this phase of the subject.

\section{COMPARISON OF VARIOUS TYPES OF GLUE.}

Each of the five types of glue, namely, animal, casein, vegetable, blood, and liquid, has its own peculiarities, properties, and uses which influence its suitability for various purposes.

Animal glue has been used so long and is so familiar to woodworkers that the value of other glues is measured by comparing with animal glue. The principal desirable properties of animal glue are the great strength and reliability of the higher grades, its free-flowing consistency, and the fact that it does not cause staining of fancy veneers. So far no glue has been found by the woodworking industry to be as suitable as animal glue for hand spreading on irregularly shaped joints, although a cheaper glue would be very desirable. The price of animal glue and the fact that it is not highly water resistant are the chief factors which limit its use.

Casein giue has been used commercially for such a short time that its possibilities and limitations are not well known. It has good strength, is used cold, and can be spread with a brush, all of which are desirable properties. The property most featured, however, is its high water resistance, which makes it suitable for gluing articles to be used under moist conditions. This property makes it a very desirable glue for special purposes. 
Among the disadvantages of casein glues are their tendency to stain thin veneer and the relatively short working life of some kinds. They are also said to be somewhat harder on tools than animal and vegetable glues. This may be overcome possibly by using different steel in the tools, or perhaps by altering formulas.

Casein glues by proper manipulation can be given certain special properties, as desired. Their water resistance, strength, consistency, spread, and cast can be varied orer wide ranges by one thoroughly familiar with the subject. This is true to a much greater extent of the wet than of the prepared casein glues. Already considerable reductions in cost have been made in both kinds, but particularly in the wet glues. It seems quite probable that casein glues will some day be serious competitors of vegetable glues on a price basis, without regard to water resistance or other properties. Already they are entering the field of animal glue in joint work. The fact that they can be made to spread readily by hand on irregular joints is in their favor in this connection, in addition to their lower price.

Vegetable glues have found wide use in recent years chiefly on account of their cheapness. Other valuable features are that they are used cold, and that they remain in good working .condition and free from decomposition for many days. They are extremely viscons, however, and it is not practicable to spread them by hand. Their lack of water resistance and the fact that they usually cause staining in thin fancy veneer are factors limiting their use.

Experimental work by manufacturers is constantly under way with the object of developing new and better grades of vegetable glue, and some progress has been made toward producing a stainless grade. The future developments in this line depend to some extent upon decisions in patent litigation.

Blood albumin glue has shown notably high resistance to moisture, especially in the boiling test. This makes it particularly suitable for gluing plywood which is later to be softened in hot water and molded. The production of molded plywood articles has been very limited, but it offers a good field for future development.

Blood glue formulas can be altered so as to produce glues of various properties. It is possible to make some very cheap blood glues suitable for the production of medium or cheap grade articles. A very valuable form in which it can be made is the dry glue tissue. This promises to be valuable for laying fancy veneers, since by its use it is possible to eliminate much of the trouble due to moisture changes. The factors limiting the use of blood glue are the expensive apparatus required, the relatively low production per press, and the fact that it is not very practical for gluing thick stock.

Liquid glues are, in general, similar in properties to animal glue. Some brands are quite equal in strength to good joint glues, but other brands are very weak and unreliable. Their great advantage is that they come in prepared form, ready for immediate use. This makes them particularly suitable for patch work and small gluing jobs. The factors which limit their use are their high price, their lack of water resistance, and the diffieulty the manufacturer has in distinguishing between good brands and poor brands.

The following table gives in summarized form a comparison of the various glues. From the table and the preceding discussion it will be seen that there is no glue which is superior in all respects to all the others. 
Oomparison of various gtues.

\begin{tabular}{|c|c|c|c|c|c|}
\hline Particular compared. & Animal gluo. & Casoln glue. & Vegetable glue. & Blood glue. & Liquid glue. \\
\hline Souree. & $\begin{array}{l}\text { Animal hides, bones, } \\
\text { etc. }\end{array}$ & Casein from milk. & $\begin{array}{c}\text { Starch-generally cas- } \\
\text { sgva. }\end{array}$ & Soluble dried blood. & $\begin{array}{l}\text { Apimal glue, or shing, } \\
\text { bones, ete., of ish. }\end{array}$ \\
\hline $\begin{array}{l}\text { Cost per pound (Apr., } \\
\text { 1919); (veneer glue } \\
\text { prices for carload } \\
\text { lots). }\end{array}$ & $\begin{array}{l}\text { High grade, } 25 \text { to } 42 \\
\text { cents per pound; } v e- \\
\text { neer grades, } 15 \text { to } 30 \\
\text { cents per pound. }\end{array}$ & $\begin{array}{l}\text { Caseln, } 14 \text { to } 18 \text { conts } \\
\text { per pound; prepared } \\
\text { casein glues, } 16 \text { to } 20 \\
\text { cents per pound. }\end{array}$ & $\begin{array}{l}\text { Prepared glue, } 10 \text { to } 12 \\
\text { cents per pound: } \\
\text { starch, } 8 \text { to o cents } \\
\text { per pound. }\end{array}$ & $\begin{array}{l}\text { Drled blood, sbout } 20 \\
\text { cents per pound. }\end{array}$ & $\$ 1$ to $\$ 5$ per gallon. \\
\hline $\begin{array}{l}\text { Spread L- } \\
\text { Extremes reported: } \\
\text { Oommon range: }\end{array}$ & $\begin{array}{l}20 \text { to } 45 \\
25 \text { to } 35\end{array}$ & $\begin{array}{l}30 \text { to } 80 . \\
35 \text { to } 55 .\end{array}$ & $\begin{array}{l}35 \text { to } 70 . \\
35 \text { to } 50 \text {. }\end{array}$ & 80 to 100. & No data. \\
\hline Miring. & $\begin{array}{l}\text { Sosked in water, then } \\
\text { melted. }\end{array}$ & $\begin{array}{l}\text { Mixed cold, } \\
\text { rapid stiliring. }\end{array}$ & $\begin{array}{l}\text { Mixed with alkgli ond } \\
\text { water, with or with- } \\
\text { out beat can be } \\
\text { made without alkail. }\end{array}$ & Mixed cold. & $\begin{array}{l}\text { Requires no prepara } \\
\text { tion. }\end{array}$ \\
\hline Appllcation. & $\begin{array}{l}\text { Applied warm with } \\
\text { brush or mechanical } \\
\text { spreader. }\end{array}$ & $\begin{array}{l}\text { Applied cold with } \\
\text { brush or mechanical } \\
\text { spresder. }\end{array}$ & $\begin{array}{c}\text { Applied cold with } \\
\text { mechaniesl spreader. }\end{array}$ & $\begin{array}{l}\text { Applied cold by hand } \\
\text { or with mechanical } \\
\text { spreader. }\end{array}$ & $\begin{array}{l}\text { A pplied cold or warm, } \\
\text { usually by hand. }\end{array}$ \\
\hline Temperature of press. & $\begin{array}{l}\text { Cold; hot eauls fre- } \\
\text { quently used. }\end{array}$ & Cold. & Cold. & Hot. & Cold. \\
\hline $\begin{array}{l}\text { Strength (block shear } \\
\text { test). }\end{array}$ & $\begin{array}{l}\text { High grade oqual in } \\
\text { shear strength to } \\
\text { strongest American } \\
\text { woods medium } \\
\text { grades sightly lower. }\end{array}$ & $\begin{array}{l}\text { Bimilar to medium- } \\
\text { grade anlmal glue. }\end{array}$ & $\begin{array}{l}\text { Simillar to or sllghtiy } \\
\text { less than medium- } \\
\text { grade animal glue. }\end{array}$ & $\begin{array}{l}\text { Slmilar to or slightly } \\
\text { less than madium- } \\
\text { grade animal glue. }\end{array}$ & $\begin{array}{l}\text { Good grades similar to } \\
\text { mediunl-grade ani- } \\
\text { mal gl ue; so me } \\
\text { brands very weak. }\end{array}$ \\
\hline Water resistance. & Low. & Inigh, & Low. & Hilgh. & Low. \\
\hline Staining. & Does not stain. & $\begin{array}{l}\text { Stains thin yeneer of } \\
\text { some specles. }\end{array}$ & $\begin{array}{c}\text { If mixed with caustic } \\
\text { soda, stains thin re- } \\
\text { neer of some species. }\end{array}$ & $\begin{array}{l}\text { Doesmotstain, but the } \\
\text { glue is very dark; } \\
\text { dryprocess gluedoes } \\
\text { not show through. }\end{array}$ & Does not stain. \\
\hline Uses in woodworking. & $\begin{array}{l}\text { Figh grade, whare a } \\
\text { strong joint is de- } \\
\text { sired; low grade, } \\
\text { sometimes used lor } \\
\text { veneering, especislly } \\
\text { where it is desired } \\
\text { to prevent staining. }\end{array}$ & $\begin{array}{l}\text { Mainly where water } \\
\text { resistance is desired } \\
\text { in veneered or joint } \\
\text { work. }\end{array}$ & $\begin{array}{l}\text { Mainly in veneered } \\
\text { work on accotunt of } \\
\text { cheapness, but glso } \\
\text { somewhat for foint } \\
\text { work. }\end{array}$ & $\begin{array}{l}\text { Almost entirely for } \\
\text { water-resistant ply- } \\
\text { wood for aircraft } \\
\text { purposes and for ax- } \\
\text { tioles to be molded } \\
\text { after bolling in wo- } \\
\text { ter. }\end{array}$ & $\begin{array}{l}\text { Mainly for repair Frork } \\
\text { and gluing small sr- } \\
\text { tictes by hand. }\end{array}$ \\
\hline
\end{tabular}

2 Expressed in square feet of glue line per pound of dry glue for veneer work.

\section{TESTING GLUES.}

The tests used in judging glue vary with the types. Strength tests are suitable for all types. Water-resistance tests are made on casein and blood glues. Additional tests made on animal glues are with respect to viscosity, jelly strength, odor, keeping qualities, grease, foam, and reaction to litmus. Chemical analysis is generally of little value in judging glue.

\section{STRENGTH.}

\section{BLOCK SHEAR TEST.}

Strength tests are made by gluing together two or more pieces of wood and noting the pressure or pull required to break them apart. A number of methods of making the test specimens and breaking them have been devised. These depend to a certain extent upon the character of work expected of the glue and the nature of the testing apparatus available. In the experiments at the Forest Products Laboratory the simplest and most convenient method found for testing the strength of the glue is a shear test.

Two blocks of selected hard maple, about 1 by $2 \frac{1}{2}$ by 12 inches in size, are glued together. After the glue has aged sufficiently they are cut into shear specimens as shown in figure 1. These are placed in a testing machine so that the base of the long half of the block rests on 


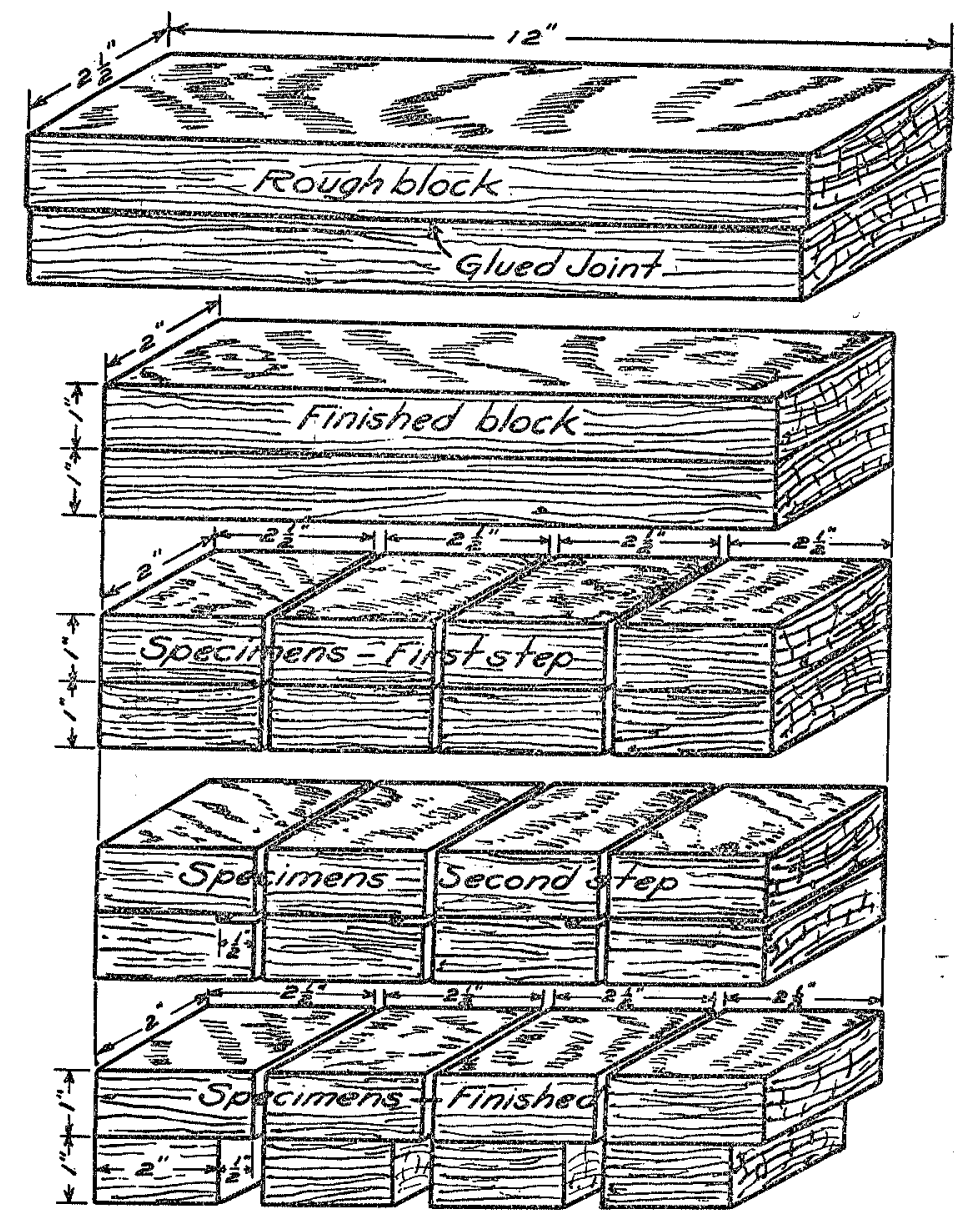

Fia. 1,-Method of preparing specimens for glue strength tests. 
a metal seat. (See fig. 2-C.). Pressure is then exerted on the short half, causing it to slide past the long half at the glued joint. The pressure required to separate the blocks in this way is measured and the percentage of the area of wood surface torn out by the glue estimated.

If the failure occurs entirely in the glue, a measure of the strength of the glued joint is obtained, but if the failure is entirely or partly in the wood, as frequently happens, the full strength of the glue is not developed, and the test may have to be repeated using stronger blocks.

The same method has been used in securing data on the strength of wood in shear. Consequently when the strength of gliee has been determined it can be compared with that of any wood whose average shearing strength is known.

Four specimens are usually broken and an average taken of their individual values. The variation in the values can be kept at a minimum if the specimens are selected, prepared, and tested under as nearly the same conditions as possible. A very important factor is the selection

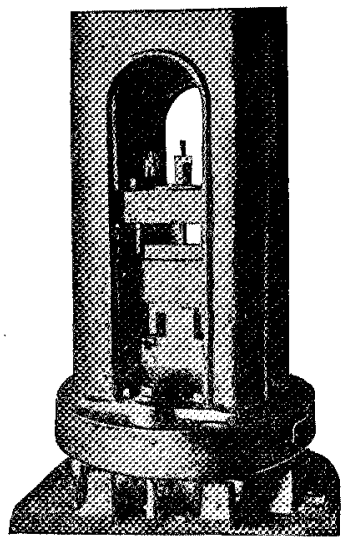

A
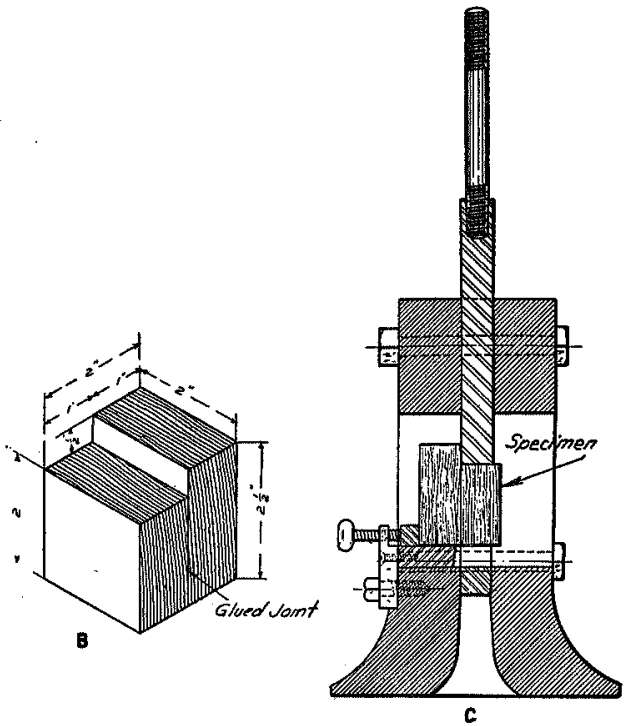

C

FIG. 2.-Shear block test specimen and shearing tool.

of the wood. The species should be the one upon which it is proposed to use the glue, or one ut least equally strong. Hard maple is the standard wood in use at the Forest Prodncts Laboratory. Other woods of equal or greater strength which might be used are sweet birch, black locust, flowering dogwood, canyon live oak, persimmon, big shellbark hickory, and western yew.

It is a good plan to test hide glue at three or four different dilutions. Four different sets of specimens should therefore be prepared, using $2,2 \frac{1}{4}, 2 \frac{1}{2}$, and 23 parts water, respectively, to one part of glue. An exceedingly high-grade glue may work best at three to one, and there are low grades which will give best results with less than two parts of water to one of glue. Other types of glue should also be tested under conditions which will permit them to develop their full strength.

On account of the variable nature of wood and the impossibility of doing perfect gluing, the test is far from perfect as an absolute measure of the strength of a glue, but no other 
strength test has been found to be nearly so good. It merely gives an idea of the ability of. the glue to hold wood together. If only one or two speeimens are tested, the results are apt to vary widely and be misleading, so it is desirable to base conclusions upon data from a considerable number of tests.

As a means of judging whether the glue is being used to the best advantage, the shear block test is very valuable. The specimens can be prepared from almost any piece of glued work, provided the laminations are not thinner than about one-fourth of an inch and the grain in adjacent laminations runs parallel. It is preferable that the specimens be cut to the size shown in figure 2 , but it is not absolutely necessary; smaller sizes can be used if conditions require.
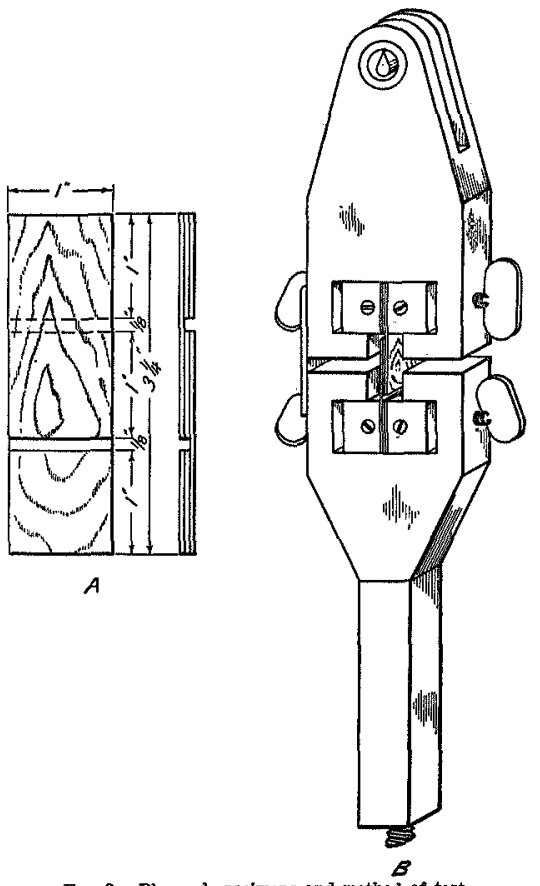

Fig. 3.-Plywood specimens and method of test.

PLYWOOD SHEAR TEST.

An additional strength test is made on glues used for the manufacture of plywood. This consists of shearing the plies apart. The form of specimen used at the Forest Products Laboratory is the one used during the wan by the British and American Governments in testing aircraft plywood, and is shown in fig. 3-A. It is simple, easily prepared from any plywood panel and quickly tested. The machine used in the test is the type designed for testing cement, but is provided with special grips as shown in fig. 3-B. The specimen is placed under tension and fails principally from shearing. The shape of the specimen makes it impossible to develop the full shearing strength, but the test gives comparable results and serves to keep a close check on the uniformity of the product. 


\section{WATER RESISTANCE.}

So-called waterproof glues may be tested by soaking or boiling specimens of plywood glued with them. The specimens used at the Forest Products Laboratory are 5 by 5 inches in size. The specimens are soaked for 10 days or boiled for eight hours and the results tabu-

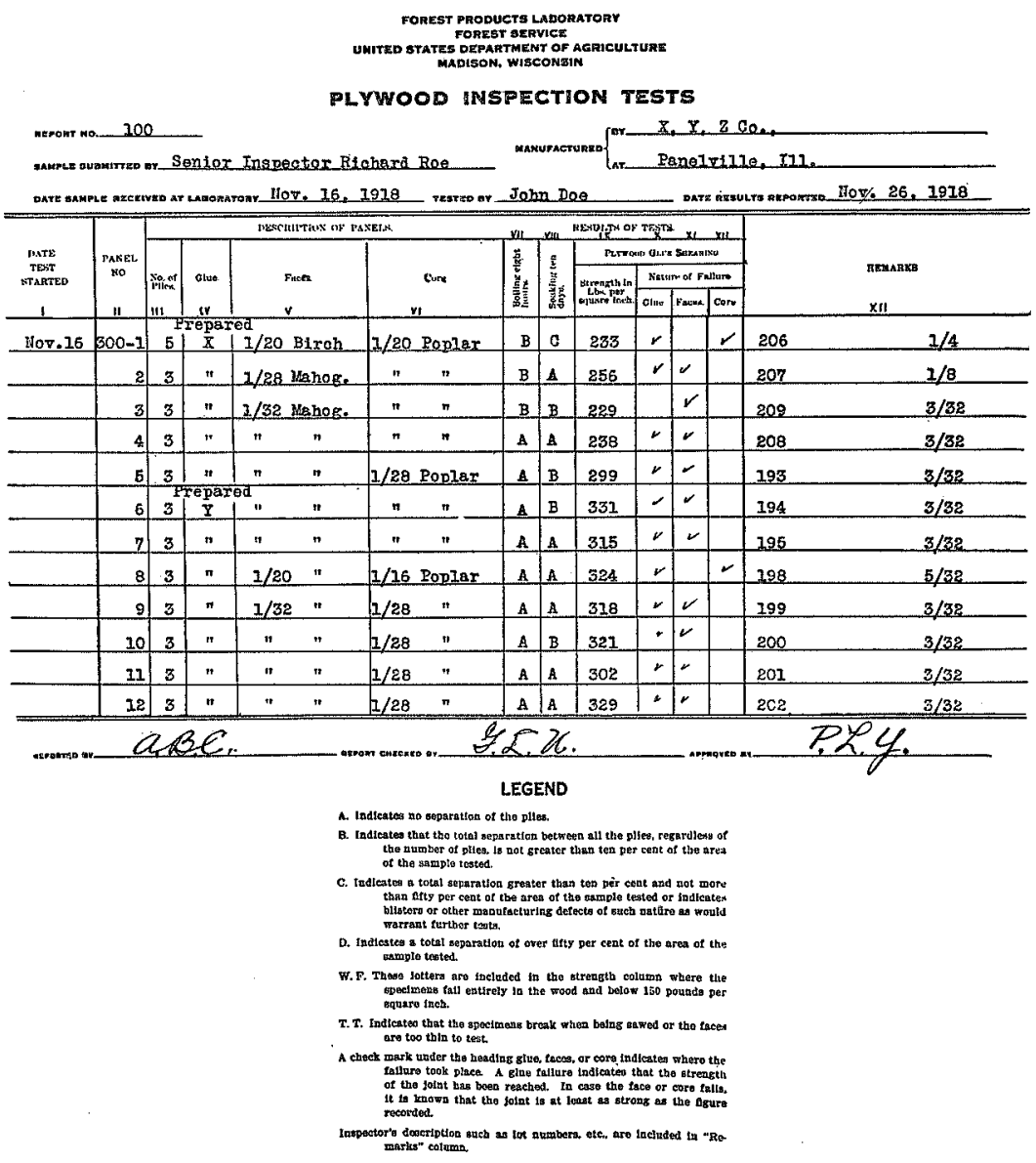

Fic. 4.-Form for reporting routhe plywood tests, flled out with actual figures from typical test.

lated on the form shown on fig. 4. The latter test, while not designed to duplicate any actual service condition, amounts to an accelerated soaking test and furnishes comparable results in a short time. If a more accurate test of water resistance is desired, plywood shear specimens may be cut, then boiled or soaked, and tested in the usual way in the plywood testing machine. 


\section{VISCOSITY.}

The viscosity of animal giue is determined by allowing a specified amount of the glue at a definite temperature (usually $140^{\circ} \mathrm{F}$.) to flow through a standard orifice. The time required is a measure of the viscosity. The time required for water to flow through is taken as the standard. In general, it is found that a glue with high viscosity is stronger than one of low viscosity and will take more water, although there are exceptions. Hide ghes, as a rule, have higher viscosities than bone glues. A number of viscosimeters of different shapes have been devised. In the glue manufacturer's laboratory, where many tests must be made each day, an instrument must be used which will give results quickly. This can be done with a pipette, cut off at one end, or with a straight glass tube contracted at one end. These instruments are not always so arranged that the temperature of the glue within them can be controlled, and for a number of other reasons they are not entirely accurate. For better control of temperature and greater accuracy the Engler viscosimeter is often used. This is more complicated and more expensive than the glass tubes, and also slower to operate, but it has the advantage, in addition to greater accuracy, of being an instrument which is in general use for testing many kinds of materials. The values obtained by its use are readily understood by laboratory men and can be readily checked. The instrument can be purchased standardized and ready for use.

\section{JELLY STRENGTH.}

The term jelly strength refers to the firmness or elasticity of the jelly formed by cooling a glue solution of specified strength. Strong animal glues usually have high jelly strength. There is no standard instrument for determining it, and no standard unit for expressing it. In some laboratories the pressure required to break the surface of the jelly is measured. In others the depth is observed to which a weight of special shape will sink. Sometinnes the jelly is cast in a conical shape and the weight required to press the point of the cone a certain distance is taken. The Smith jelly tester, which is sometimes used, is so constructed as to measure the pressure required to expand a rubber diaphragm into the jelly to a certain volume. This instrument is generally considered too inconvenient and slow, but it enables an accurate comparison to be made and is used by some testing laboratories. A very common test is the finger test, in which the relative strength of two or more jellies is compared by pressing the jelly with the fingers.

In making the jelly-strength test with any apparatus it is important that the conditions be very carefully controlled in order that comparable results may be obtained. The width and depth of the glue jelly should be as great as practicable, in order to reduce to a minimum the reinforcing effect of the bottom and sides of the vessel upon the resistance of the jelly to indentation. Once a standard is adopted it should be adhered to if comparative results are desired. The temperature of the jelly when tested is particularly important, as the relative strength of a number of jellies is not always the same at different temperatures. In other words, the jelly strength of different glues is not affected to the same extent by changes in temperature. The ideal way would be to cool and test the jellies in a room constantly maintained at the proper temperature. This is seldom practicable, however, and the jellies are generally cooled in a refrigerator and tested in a warmer room. In such cases it is important that the test be made as quickly as possible after removing the jelly from the refrigerator, so that the temperature will be practically the same as it was in the refrigerator. The strength of the glue solution must also be always the same, once a standard is adopted. Weaker solutions can be used for high-strength glues than for low-strength glues.

\section{ODOR.}

The odor of animal glue gives some indication of its source and its condition. Glue which has an offensive odor is not considered of the highest grade. The bad odor may be due to the use of partly decomposed stock, or to decay of the glue itself. For high-grade work it is 
usually specified that the glue be sweet; that is, it must not have an offensive odor, which is determined by smelling a hot solution of the glue. The odor of different glues varies considerably, and it is difficult or impossible to express the different "shades." It is usually not difficult, however, to determine whether or not the odor is clean, or, as it is commonly called, sweet. The temperature and strength of solution are usually not specified.

\section{KEEPING QUALITY.}

The keeping quality of a glue is determined by allowing the jelly left from the jellystrength test to stand in the laboratory at room temperature for a number of days. The odor and condition of the glue are noted at intervals. Glues with good keeping qualities will stand several days without developing an offensive odor, or showing any appearance of decomposition. A more rigorous test frequently adopted is to keep the solution in a thermostat at about $35^{\circ} \mathrm{C}$. The glue should remain sweet at least 48 hours under these conditions.

\section{GREASE.}

For joint work a small amount of grease in glue is not a serious objection. Too much grease, however, is objectionable, as grease has no adhesive properties. For some classes of work, such as paper sizing, even a very small amount of grease can not be tolerated, as it gives the paper an objectional appearance. When glue is to be used in a spreader where foaming is likely to occur, a small amount of grease is desirable, as it retards forming. The grease can be determined by chemical means if desired, but this is not necessary unless the exact amount of grease must be determined. The common method of testing for grease is to mix a little dye with the glue solution and paint it upon a piece of unsized white paper. If grease is present, the painted streak will have a mottled or spotted appearance. If there is no grease, the streak will be uniform.

\section{FOAM.}

Glue which foams badly is objectionable because air bubbles get into the joint and thus reduce the area in which the glue is in contact with both faces. Foamy glue is especially undesirable for use in gluing machines, as the glue is agitated much more than when it is used by hand, and the danger of incorporating air bubbles is greater. The amount of foam is determined by beating the glue solution for a specified time with an egg beater or similar instrument and then noting the height to which the foam rises and the quickness with which it subsides. All laboratories do not make the test in exactly the same way, but in any laboratory after a method has once been adopted it should be strictly followed. The foam test is generally made on the solution used in the riscosity test.

\section{REACTION TO LITMUS.}

By its reaction to litmus a glue shows whether it is acid, alkaline, or neutral. The test is made by dipping strips of red and blue litmus paper in the glue solution remaining after the viscosity test or some other test, and noting the color change. An acid glue turns blue litmus red, an alkaline glue turns red litmus blue, and a nentral glue will not change the color of either red or blue litmus. A glue containing a slight amount of acid is slightly preferable to one which is neutral or alkaline, because it is not quite so favorable a medium for the growth of the organisms which cause decay.

\section{COMPARISON WITH STANDARD SAMPLE.}

It is apparent that, for the most part, the tests for animal glues give comparative rather than absolute results. It is frequently difficult to compare the results of tests made by one laboratory with those made by another, as the strength of solution, temperature, and manipulation so often are different. For this reason, it is considered that the most satisfactory method 
of purchasing animal glues is to specify that they shall be equal to a standard sample furnished the bidder to test in any way he sees fit. The bidder should also be informed as to the methods the purchaser intends to use in testing glue submitted to him as equal to the standard sample.

In using strength tests it shonld be remembered that there is a difference between testing the glue itself and testing the workmanship of the gluing. In the former a wood which will not fail before the glue fails should be used. If the glue is too strong the ideal testing wood is hard to find, but hard maple approaches the desired standard. In the latter it is only necessary to use the particular wood which will be glued in practice or some other wood equally strong. Then if the glue proves stronger than the wood, the test is satisfactory.

While in some cases equipment for strength tests would pay a large manufacturer, for smaller plants the cost is prohibitive. A system of inspection and certification for glues of various grades, such as was operated in connection with the control of glue purchased for aircraft manufacture during the war, would enable purchasers to secure glue of known quality without testing it themselves. Under this system glue was barreled, sealed, and certified at the plants on the basis of actual tests made at a central testing laboratory by glue experts. This system might be duplicated during peace times by the organization of an inspection service supported by an association of the glue-using industries. 